\section{Gender equality in oncology \\ The importance of representation}

\begin{tabular}{|c|c|}
\hline $\begin{array}{l}\text { The field of oncology has a } \\
\text { gender imbalance, with women } \\
\text { only occupying a small number } \\
\text { of leadership positions. So how } \\
\text { can we improve gender equality } \\
\text { in oncology? Dr Pilar Garrido, } \\
\text { Dr Anna Sophie Berghoff, Dr } \\
\text { Cristiana Sessa and colleagues, } \\
\text { from the European Society for } \\
\text { Medical Oncology (ESMO)'s }\end{array}$ & $\begin{array}{l}\text { he European Society for Medical } \\
\text { Oncology (ESMO) is the leading } \\
\text { professional organisation for } \\
\text { medical oncology and the society of } \\
\text { reference for oncology education and } \\
\text { information. ESMO connects oncology } \\
\text { professionals with diverse expertise } \\
\text { and experience, with the ultimate } \\
\text { goal to secure the best possible } \\
\text { outcomes for patients. }\end{array}$ \\
\hline $\begin{array}{l}\text { Committee, are monitoring } \\
\text { the representation of female } \\
\text { oncologists. Through discussion, } \\
\text { education, and collaboration, } \\
\text { change can be achieved. }\end{array}$ & $\begin{array}{l}\text { With over } 25,000 \text { oncology professionals } \\
\text { from more than } 40 \text { specialties, who } \\
\text { practice in } 160 \text { countries all over } \\
\text { the world, the ESMO community is } \\
\text { incredibly diverse with constantly } \\
\text { broadening horizons. That is why a } \\
\text { key aim within ESMO is to support all } \\
\text { these oncologists in their professional } \\
\text { development as they choose their } \\
\text { different career paths. In order for this } \\
\text { to happen effectively, all oncologists } \\
\text { must be taken into account to be equally } \\
\text { represented and given the same career } \\
\text { opportunities, particularly considering } \\
\text { that } 40 \% \text { of ESMO members are young } \\
\text { oncologists under the age of } 40 \text { and, } \\
\text { among them, more than half are women. }\end{array}$ \\
\hline
\end{tabular}

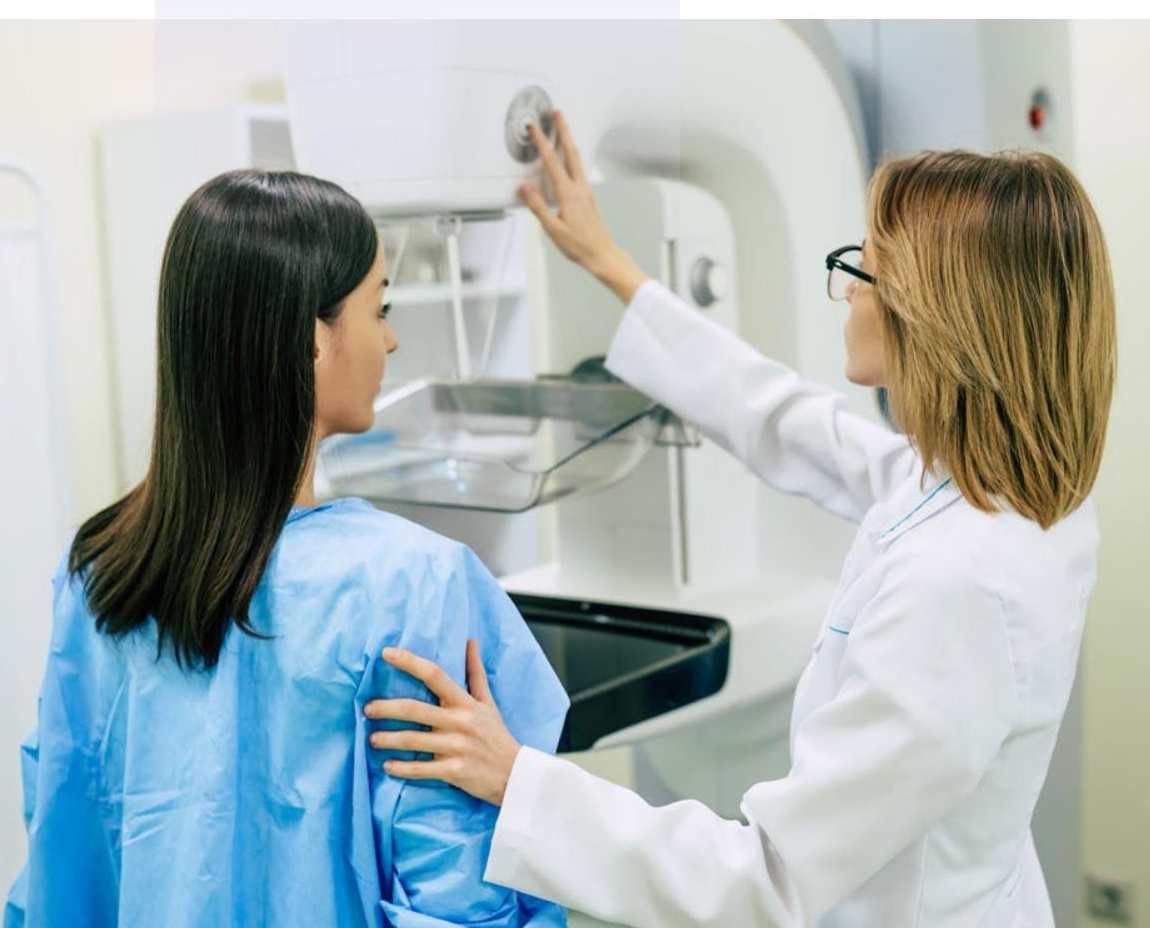

A GENDER GAP IN ONCOLOGY Many scientific fields have been shown to have a gender imbalance. For example, women are less likely than men to be promoted to a senior position or to be Invited as a speaker at a conference.
Exploratory research conducted by ESMO also showed this to be true in oncology and this led the Society to form the ESMO W4O Committee in 2015. While progress has been made over time, it appears to have stalled somewhat in more recent years. The number of women entering the field, however, is increasing, with $47.5 \%$ of ESMO members being female according to data as of 31 December 2019.

The ESMO W4O Committee aims to draw attention to these issues and raise awareness of the gender gap in oncology. To begin with, they are sensitising the oncology community to this gender vequally leadership positions through various studies. This leads to more open conversations which, in turn, can cause professionals together to exchange resources and encourage collange for female oncologists which can advance careers and lead to new opportunities. Sharing challenges and aspirations. allows local initiatives to respond to their members' specific needs. Finally, W4O sessions at ESMO Congresses allow dissemination of all this information and research. This also provides another opportunity for female oncologists to discuss career development and to meet inspirational women leaders.

THE IMPORTANCE

OF FEMALE AUTHORSHIP

W4O investigates the gender imbalance in oncology through studies that focus on
the gender gap in career development

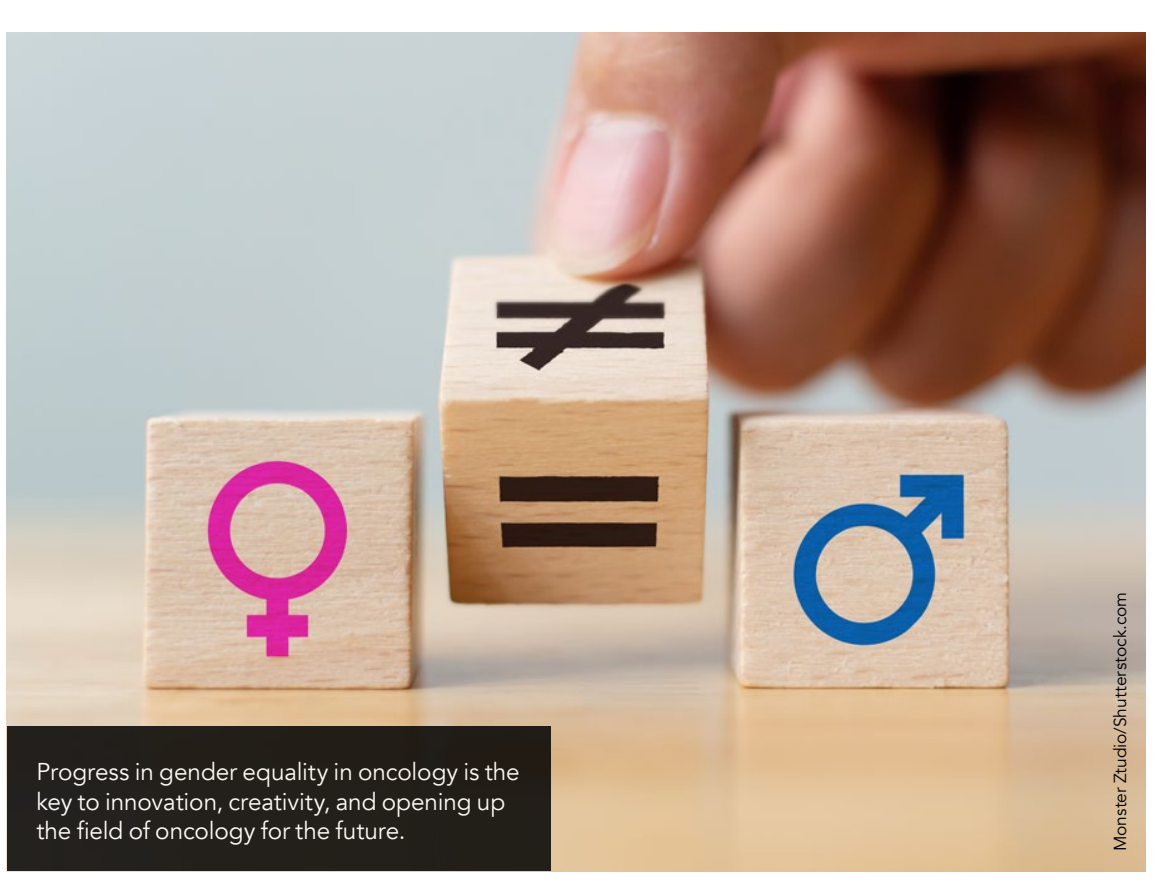

and by monitoring the progression of female oncologists into positions of more female researchers, the majority of disseminated across countries to raise

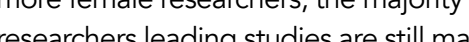
gender inequality

Sensitising people to gende First, W40 carried study to assess the representation of women as authors in oncology. The researchers looked at papers from five major oncology journals covering a period from 2017 to 2019. On each of these papers they checked the gender of the first and last authors listed. It was found that the percentage of female first years, ranging from $37 \%$ to $41 \%$ On the other hand the popotion of fema last authors decreased in 2018 from $30 \%$ to $24 \%$ but increased again in 2019 to $28 \%$. It was also discovered that women were more likely to be first authors than last authors throughout these years.

The results from this authorship study in comparing the genders of first and authors can tell us a lot about the field of oncology. Usually, the first author is the person who wites the paper and carries out most of the research, while the last author is often the senior project leader. If the numbers of female first authors a increasing, this could mean that more romern are conducting and witing not being seen for female last authors.

the journals and more likely to be found in special sections. There are more it is important to note that wor therefore underrepresented here.

Another discovery from this study was that on average, the h-index was lower for women than for men. The h-index measures an author's productivity of citations they have had. It is used to assess the quality of an author's work. However, if we are seeing lower percentages of women authors than men this will affect the $h$-index, in turn leading to a vicious cycle.

\section{FEMALE REPRESENTATION IN} LEADERSHIP POSITIONS Another way in which $W 4 \mathrm{O}$ assessed gender equality in oncology was representation of women speaker at oncology congresses, and as board members and presidents of oncology societies. They looked
at 180 different international and national conferences from 2015 to 2019 throughout which there were 35,113 speakers. It was found from the data that can cause change.

As well as authorship, gender representation throughout the different women were significantly less likely to sections of these journals was analysed. to men. Information from each of less likely five years showed that well below to be included in the main sections of the speakers were women. However,

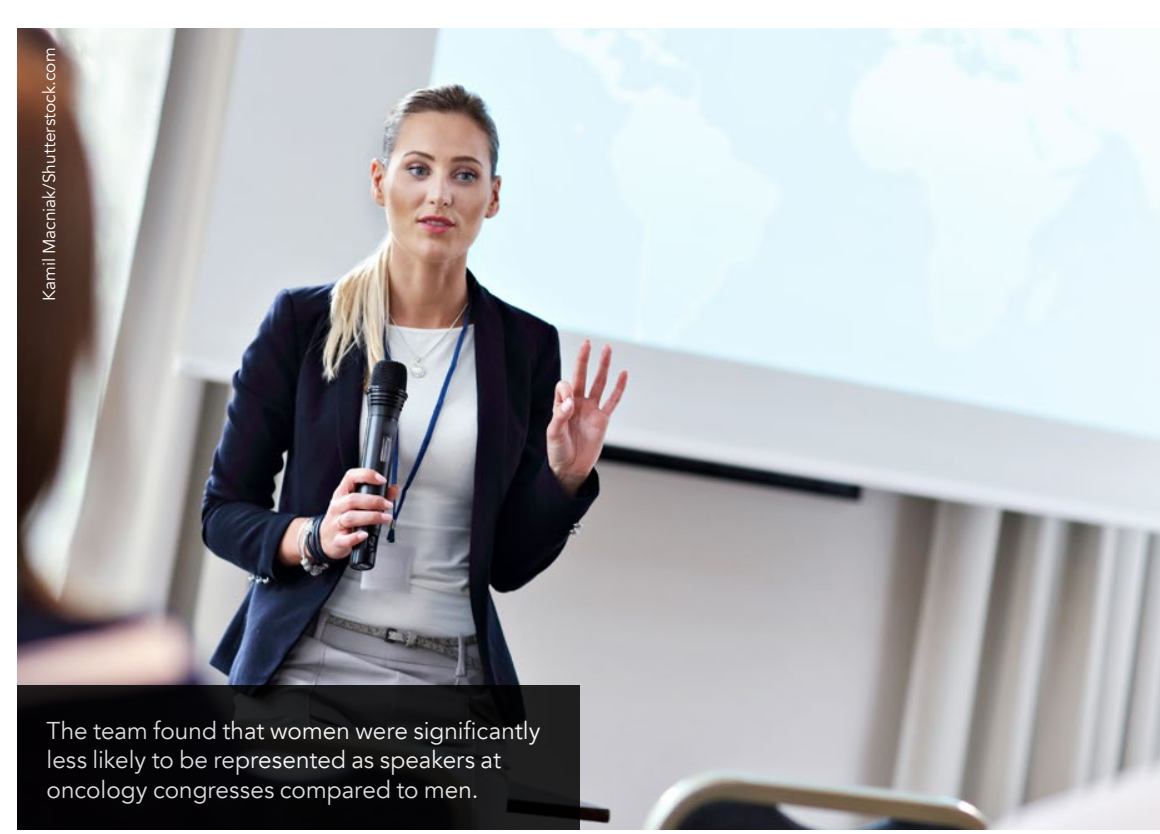




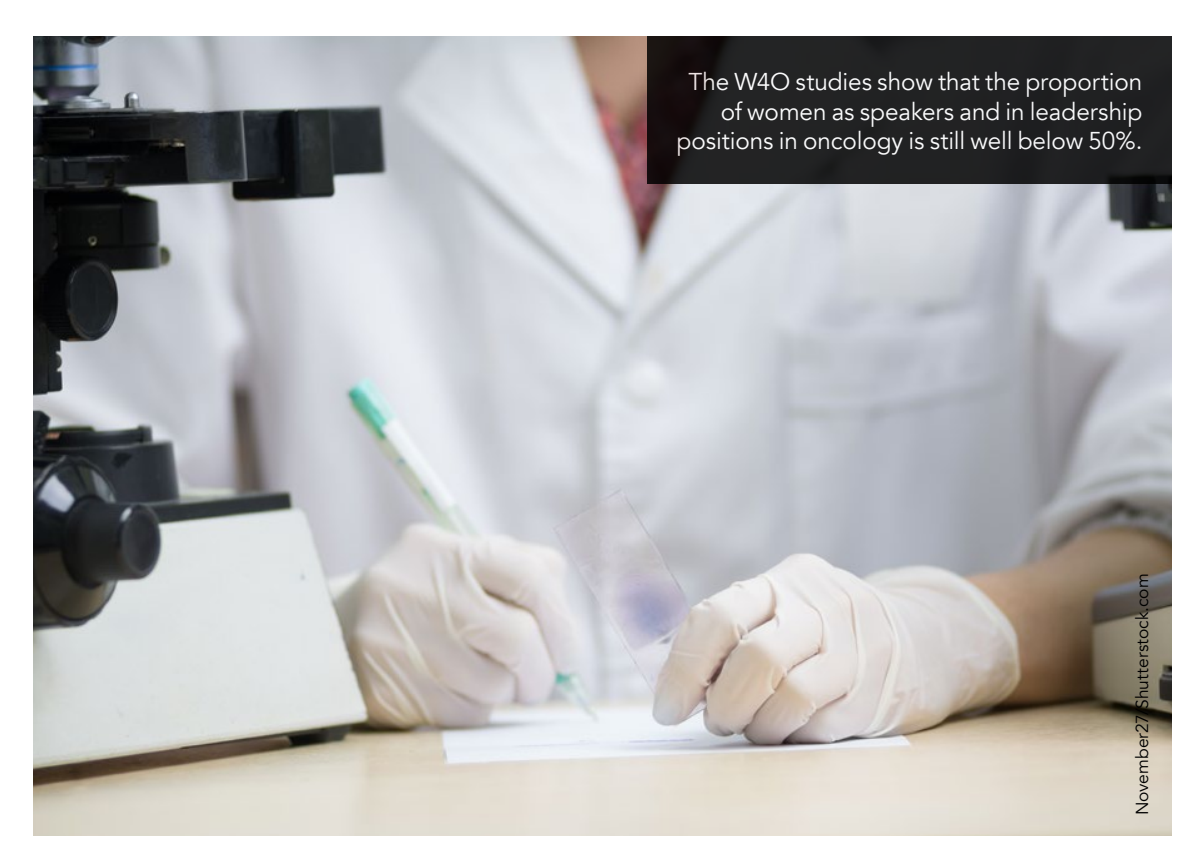

the percentage of female speakers did increase from year to year. While in femal this had increased to roughly 37\% by 2019. This is not an enormous difference but shows an upwards trend over the years.

These upward trends of female representation in oncology were seen at international conferences, but only in certain regions at national conferences. For example, conferences in Europe and South America had steadily increasing numbers of female speakers, board members and presidents, but this was much lower or not seen at all in Asia or Oceania. Knowing about these focus for outreath in the future of

Throughout these same five years from 2015 to 2019, women were much less likely to be board members of oncology societies than men. These numbers increased over the study similarly to the percentage of female speakers: however, they are still far too low. These results show again the gender inequality in the field of oncology. Finally, the gender of the presidents of these societies was also looked at. Following the same trend, the presidents were less likely to be female than male, with percentages increasing slightly over the period of the study. This was the lowest of all the data collected with only $22 \%$ of presidents being female, confirming the under-representa
leadership positions. in leadership positions in oncology is still well below $50 \%$. The slow far from reat enough, and we are oncology These increases can only be helped by more initiatives such as the W4O within ESMO which keeps the gender discussion high on the public agenda. These studies are ongoing as $\mathrm{W} 4 \mathrm{O}$ continues to investigate female representation at an international level in the long term. Monitoring the situation to provide more information and draw attention to the topic of female empowerment can only lead to positive change for future emale oncologists, as well as women already in the field.

Progress in gender equality in oncology is vital. The importance of female

An important discovery worth highlighting was that there was an association between female speakers and female board members. Societies where wome sit is the key to innovation, creativity, and opening up the field of oncology for the future. More importantly, it is simply fair. The diverse members of ESMO must all be offered the

were much

We are far from reaching gender equality in oncology; more must be done to enhance the careers of female oncologists.

as speakers at their conferences. Equally, same opportunities for equality female presidents were more likely to to be reached. The importance of have female board members. representation of women in leadership THE FUTURE OF ONCOLOGY These W4O studies show that the young women will be inspired to pursue proportion of women as speakers and $\quad$ greater success in the future.

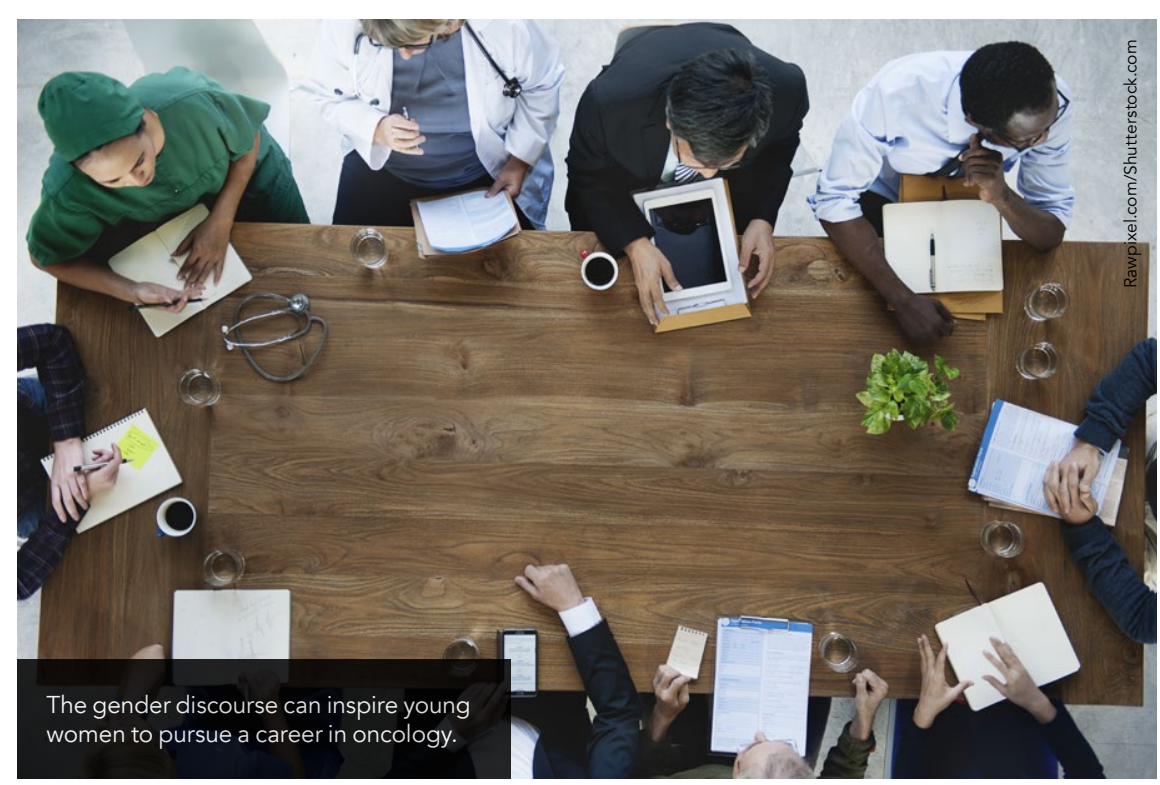

\section{Behind the Research}

Dr Anna Sophie

Berghoff

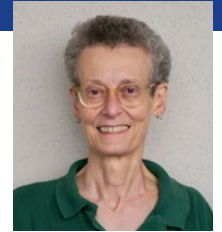

Dr Cristiana

Garrido

E: communication@esmo.org W: Www.esmo.org/career-development/women-for-oncology
fwww.facebook.com/women4onco/

\section{Research Objectives}

Research conducted through the $\mathrm{W} 4 \mathrm{O}$ initiative aims to monitor the representation of women in oncology and provide a long-term, objective set of data and information, with the ultimate goal of raising

\section{Detail}

\section{Address}

Addror Oncology Committee

c/o European Society for Medical Oncology (ESMO)

Bio

Pilar Garrido is Associate Professor of Medical Oncology at Universidad de Alcalá and Head of the Medical Oncology Department's Thoracic Tumours at the University Hospital Ramón y Cajal (Madrid, Spain). President of FACME (Spanish Federation of Medical Spacieties), she was the fist Woman President of the Spanish Medical Oncology Society.

Anna Sophie Berghoff works at the Clinical Division of Oncology, Medical University of Vienna (Austria) and has her clinical focus on CNS Malignancies. She completed her PhD thesis in the Clinical Neuroscience Programme German Cancer Research Center (DKFZ) .

Cristiana Sessa is clinical scientific consultant at the Oncology Institute of Southern Switzerland, Ospedale San Giovanni (Bellinzona, Switzerland). She is also University of Bern (Switzerland).

Funding

European Society for Medical Oncology (ESMO)

Collaborators

ESMO Women for Oncology Committee

\section{References}

Berghoff, AS, et al, (2021) Female leadership in oncologyhas progress stalled? Data from the ESMO W4O authorsh ip and monito sing studies. ESMO Open [in press]. doi. of $10.1016 / j . e s m o o p .2021 .100281$

Hofstädter-Thalmann, E, et al, (2018) Report on the status of women occupying leadership roles in oncology. ESMO Open, 3(6). www.esmoopen.com/article/S20597029(20)30218-0/fulltext

\section{Personal Response}

Are you planning any outreach activities in the future? II The results of the ESMO W4O studies are presented at the W4O Forum, taking place yearly on occasion of the ESMO Congress (which counts over 30,000 participants
from all over the world). In addition to that, the W4O from all over the world). In addition to that, the W4O Committee disseminates the results of their studies through regular publications in oncology jounnals, by making them
available on the ESMO website and through communication
campaigns on social media.

How are you planning to advance your research?

II The ESMO W4O monitoring and authorship study
is a longitudinal research, running in circles of three is a longitudinal research, running in circles of three years. The $W 4 \mathrm{O}$ Committee is currently collecting data has been expanded by increasing the number of oncology journals covered and by collecting data on their editorial board composition. In addition to this, an exploratory study on gender-related issues has been launched in the Asian Region to inform future activities
by ESMO W4O in the region.

\section{WOMEN FOR ONCOLOGY}

An ESMO Initiative 